\title{
Using IT to Support Knowledge Management - A Survey- Based Study of a Large, Global Consulting Company
}

\author{
Karlheinz Kautz \\ Copenhagen Business School, Frederiksberg, Denmark
}

Karl.Kautz@cbs.dk

\begin{abstract}
The paper reports the results of a quantitative, survey-based study which investigates the use of an IT supported knowledge management system (KMS) which is embedded in knowledge management framework in a large, global IT consulting company. The main findings are that the majority of the IT users are not familiar with the KMS framework. Still, the KMS is used by 3/4 of all respondents, but mainly to search for general information, but much less to participate in competence networks to develop shared knowledge assets. The KMS is not used as the primary repository and communication media for knowledge assets. The limited use is explained by the practitioners as being caused by lack of time and their perception of the KMS as a slow and poorly structured technical infrastructure. These and other findings are discussed with regard to the current understanding of knowledge management as presented by the literature in the field.
\end{abstract}

Keywords: knowledge management, IT support.

\section{Introduction}

Numerous publications exist discussing the concepts of knowledge and knowledge management with regard to modern economy and business. Most of them also include general consideration concerning the benefits and advantages as well as drawbacks and perils of IT support for managing knowledge (for an overview of the knowledge management literature see for example Swan et al. (1999)). However little research can be found that studies the reasons, the concrete purpose and the extent of actual use of IT support for knowledge management in organisations. This is the focus of the research presented here. Much of the existing work is based on qualitative case studies (see for example. Hansen et al. (1999), Brown \& Duguid (2000), Huysman (2000), Kautz \& Thaysen (2001)), while quantitative investigations are directed towards management and not particularly towards IT utilisation, but towards knowledge management in general (see for example. Bresman et al. (1999), Hansen (1999), Gupta \& Govindarajan (2000), Szulanski (2000)).

This paper reports the results of a quantitative, survey based study which investigates the use of an IT supported knowledge management system in a large, global IT consulting company.

The company has chosen to be anonymous. Therefore all references to company material, precise num-

Material published as part of these proceedings, either on-line or in print, is copyrighted by Informing Science. Permission to make digital or paper copy of part or all of these works for personal or classroom use is granted without fee provided that the copies are not made or distributed for profit or commercial advantage AND that copies 1) bear this notice in full and 2) give the full citation on the first page. It is permissible to abstract these works so long as credit is given. To copy in all other cases or to republish or to post on a server or to redistribute to lists requires specific permission from the publisher at Publistreए@intommingsciemce.org bers of the company's staff as well as very specific company terms have been omitted.

As the actual use of the IT supported functions of the knowledge management system is in the focus of this investigation, a detailed epistemological discussion of concepts like data, information, knowledge, wisdom or intellect, and their general impact on the use of the accompanying IT components has 
Using IT to Support Knowledge Management

only been included to a certain extent, but does not go into a level of detail as would be expected of more philosophical considerations.

The remainder of the paper is structured as follows. In the next section the case organisation's approach to knowledge management is introduced. Then the research approach is presented and the research results are described. Subsequently these are discussed with regard to current understanding about knowledge management. Finally the research method is critically assessed and further research questions are posed.

\section{Knowledge Management in the Case Organisation}

The case organisation is one of the world's largest IT service providers with more than 100000 employees in more than a 100 countries. The company distinguishes a number of business areas which are formally organised in a number of departments. Each employee is assigned to one business area and one department and work is performed in projects. Staff performance is measured with respect to chargeable customer project time. Business areas reach across formal department boundaries and the company has about 60 so-called knowledge networks which organise employees within a business area in special interest groups.

According to official company documents the organisation has - based on industry's best practice and interviews and workshops with its own consultants - developed a framework to deal with knowledge in the organisation. This initiative started in 1995 in one country. Knowledge is regarded as an asset and as intellectual capital. It is seen as a prerequisite for achieving customer satisfaction and profit. Knowledge management aims at creating and structuring knowledge assets. This is believed to enable sharing of knowledge and to (re-)use it to ultimately deliver value to customers and stakeholders.

The framework is based on the company's official value system that promotes sharing behaviour as a condition for knowledge management. It is related to the company's approach to maintain staff commitment through measurable performance goals and complemented with an economical incentive scheme. The company also underlines the usual rhetoric with regard to management support when it comes to the introduction of new procedures and tools.

At the kernel of the framework are the knowledge networks, their organisation, their processes and their technical support.

One way of organising knowledge outside any particular knowledge network and/or topic is qualifying it as general knowledge about the organisation, its employees, its services, and its products. These come about as company presentations, marketing material, staff biographies, project profiles and experience descriptions, as well as reusable product descriptions and software components. The other way of organising knowledge is in the so-called knowledge networks where topic specific knowledge about up-to-date issues like e-business, IT security, ERP systems or about timeless subjects like project management and organisational change is dealt with. Each of these networks organises between 100 to 2000 employees. Until the end of 1999 a third of all employees were officially registered as members of the overall knowledge management system.

Although these networks are considered informal, they are institutionalised in a fairly formal way. Each network as well as each area of general competence, has a formal, usually part-time and in a few exceptions full time employed leader, a routing secretary transferring submitted knowledge contributions to the respective topic experts and a steering board of up to 20 practitioners, the so-called topic experts. No clear information was available about how these are appointed. They decide whether and in what form submitted knowledge is made accessible to all other network members. In addition, a network distinguishes between two groups, the so-called educated practitioners and the usual practitioners who have different access rights to the available material. Their role is it to provide, comment and use the knowledge at their 
disposal. In principle, however all members of the knowledge management system can access all knowledge.

The knowledge management process is organised in five distinct and one overall, embedded activity. In activity one, knowledge is captured or procured; then it is rated and esteemed. If approved it is edited, formatted, categorised and structured. In activity four it is then published and finally it is used. The overall, surrounded process deals with the continuous further development of the framework and the contents of the knowledge bases. All these activities are in principal supported by all employees through their contribution of new knowledge as well as their feedback and comments concerning existing knowledge. However, although they are to be performed by different groups of employees, the activities are largely executed by the members of the steering board.

Technically the knowledge management framework is supported by a web-based information system which itself is based on a well-known groupware platform and database system. Here all submitted and approved knowledge is stored and accessible in form of documents in databases - one database is defined per knowledge network and the usual groupware applications like email, discussion fora, chat rooms, calendar functions etc. are provided in addition.

All documents are classified according to their topic and a typification scheme, which distinguishes for example. method descriptions, document templates, practical tips, marketing material, biding components, etc.; and they are of course searchable according to a number of criteria.

The framework and its IT support are geared towards the organisation's model for performing customer projects. This model consists of five phases: Phase one consists of marketing activities where knowledge utilisation in form of company presentations can and should take place, and where in phase five, the project closure, knowledge - in the rhetorics of the company - should be harvested and submitted to the knowledge management system. The other phases are concerned with carrying out the actual project and again the knowledge available in the knowledge management system should be used here.

In the following the research approach applied in the study is presented and then a closer look is taken at how in particular the IT support of the knowledge management system is used.

\section{The Research Approach}

To answer the research questions, we performed a questionnaire-based investigation, conducted a number of formal and informal interviews and studied company documents concerning its policy towards knowledge management. We also gained access to data concerning the utilisation of the databases underlying the IT support for knowledge management.

The main emphasis lay however on collecting quantitative data with regard to the usage of the company wide web-based IT components. For this purpose a survey instrument with 35 questions and about 200 attributes was developed. Most of the questions contained multiple-choice type answers, a few also allowing for qualitative statements. The questionnaire contained several distinct parts to collect personal data about the respondents, their general use of technology, their attitude towards the company's knowledge framework and their usage, respectively non-usage of the company's IT support explicitly dedicated towards knowledge management. The questionnaire was piloted twice and in the company's technology friendly environment distributed via a web-based solution. As the study was of an explorative and analytical character, no hypothesis were formulated and tested, nor were any sophisticated statistical test runs.

A specific problem in a possible population of over 100000 members was the identification of a representative sample. We had access to the data documenting the total create, read, update and delete activities in the 60 databases which administer the documents for the KMS for a period of four months in the begin- 
Using IT to Support Knowledge Management

ning of the year 2000. An investigation of a sample of $10 \%$ of the company's employees had shown that $44 \%$ of these were content as opposed to $16 \%$ who were not content with the IT support for knowledge management. The rest was neither particularly satisfied nor especially dissatisfied. On this overall positive background the research objective was to get an impression of the actual utilisation and we decided to collect data from a top user and one average user group out of the absolute top 15 networks and to contrast these when significant. With the help of the following four criteria (1) number of documents in the knowledge network database, (2) number of submitted documents to the knowledge network database, (3) number of open documents and (4) number of practitioners in relation to number of open documents, we identified a top group -i.e. the group which according to all four criteria was among the top three user groups. To give the reader an impression, concerning criteria (1) the chosen group had about 950 documents in its base as compared to 2800 of the absolute top group, (2) there had been 115 submissions as compared to a top 340, with regard to criteria (3) the chosen group represented the absolute top with 19 000 opened documents and finally with regard to criteria (4) the group had 14 open documents on average per member as opposed to 15 for the absolute top. For the average user group all numbers where naturally lower.

The top user group consisted of approximately 1400 practitioners and we thus decided to only address those who had at least opened 10 documents during the period of investigation. This left us with 304 employees who received the questionnaire in this group. Finally with regard to the average group we left it to the regional managers in the Northern European countries to spread the questionnaire which lead to the distribution of a further 229 questionnaires.

We received 125 (ca. 23\% response rate) usable answers of which 62 came from the top group and 63 from the average group. In the top group the distribution was approximately half from Europe (plus one from South Africa) and 40\% from the Americas and the rest from the Asia pacific area, for the average group all answers were of course from Northern Europe.

As we could not find any significant differences between the members of the top and the average group, nor with regard to the different geographic areas, these are as a rule not considered in the following presentation of the results. However, some tables showing the survey results for both groups have been included to illustrate their slightly different positions.

An oddity with regard to the two groups was uncovered through a control question which showed that only $58 \%$ who according to the database data had at least 10 documents opened in the investigated period considered themselves as members of this knowledge network, whereas $28 \%$ of the average group, representing formally a different network, also considered themselves as members of the network which represented the top user group. This indicates a discrepancy between the company's official concept of (membership in) an informal network and the employees' understanding of the concept of knowledge network. We will take up this finding later again.

Further possible consequences and biases of our research approach and the sample selection are discussed in the final section of the paper.

\section{Results}

In total, $72 \%$ of all respondents believe that well up to $50 \%$ of the organisation's knowledge can be codified in written documents. The precise distribution of the percentage is as follows: $24 \%$ believe that up to $20 \%$ of all knowledge can be codified, $22 \%$ think that up to $40 \%$ can be codified, and $26 \%$ say that $50 \%$ can be codified.

Concerning the question which sources they use when in need of information regarding a specific topic (see table 1), 72\% of all respondents answer that they use the data bases of the KMS. More respondents, namely $80 \%$, talk to or discuss directly with colleagues; $70 \%$ search the internet, $64 \%$ use the company's 


\begin{tabular}{|l|l|l|l|l|l|l|}
\hline & $\begin{array}{l}\text { All } \\
\text { abs. no. }\end{array}$ & $\begin{array}{l}\text { All } \\
\%\end{array}$ & $\begin{array}{l}\text { Top group } \\
\text { abs. no. }\end{array}$ & $\begin{array}{l}\text { Top group } \\
\%\end{array}$ & $\begin{array}{l}\text { Average group } \\
\text { abs. no. }\end{array}$ & $\begin{array}{l}\text { Average } \\
\text { group } \\
\%\end{array}$ \\
\hline $\begin{array}{l}\text { Talk/discuss with } \\
\text { colleagues }\end{array}$ & 100 & $80 \%$ & 48 & $77 \%$ & 52 & $83 \%$ \\
\hline $\begin{array}{l}\text { Search KMS data- } \\
\text { bases }\end{array}$ & 90 & $72 \%$ & 55 & $89 \%$ & 35 & $56 \%$ \\
\hline Search Internet & 88 & $70 \%$ & 50 & $81 \%$ & 38 & $60 \%$ \\
\hline Search Intranet & 80 & $64 \%$ & 42 & $68 \%$ & 38 & $60 \%$ \\
\hline Read book on topic & 51 & $41 \%$ & 21 & $34 \%$ & 30 & $48 \%$ \\
\hline $\begin{array}{l}\text { Use personal, exist- } \\
\text { ing knowledge }\end{array}$ & 43 & $34 \%$ & 19 & $31 \%$ & 24 & $38 \%$ \\
\hline Take a course & 34 & $27 \%$ & 10 & $16 \%$ & 24 & $38 \%$ \\
\hline Ask around & 18 & $14 \%$ & 10 & $16 \%$ & 8 & $13 \%$ \\
\hline Use KMS helpdesk & 7 & $6 \%$ & 6 & $10 \%$ & 1 & $2 \%$ \\
\hline
\end{tabular}

Table 1: Information sources

(all respondents, percentage given with regard to the total responses within the respective group)

general intranet, $41 \%$ read a book on the subject and $27 \%$ take an educational course, only $6 \%$ consult the KMS's help desk.

All respondents use email and $65 \%$ a groupware application called teamrooms to communicate and collaborate with colleagues; $58 \%$ use other than the KMS as a repository to store valuable information, half of these a document library which is also a component of the company's groupware environment.

\section{Users' Attitudes towards the IT-supported KMS}

The large majority (89\%) of the system users believes that the IT supported KMS provides the company with a competitive advantage.

Concerning the advantages of the system $66 \%$ of them see the biggest benefit in the system in the fact that - according to their perception - all codified knowledge is in principle available through it and $64 \%$ see its benefits in enabling re-use of documents. Furthermore, $35 \%$ value the possibility to find contacts, $33 \%$ appreciate it as support for their collaboration, but only $25 \%$ see the advantage in the opportunity to create knowledge and even less, namely $20 \%$, view it as an advantage that they can contribute to the collective knowledge, finally only $7 \%$ see its merits for giving explicit feedback concerning the stored knowledge.

\section{Utilisation of the KMS's Functionality}

On the direct question whether they use some functionality of the KMS 76\% answered with yes, $27 \%$ use it up to one hour a week, $43 \%$ between 1 and 5 hours and $15 \%$ more than 5 hours a week and nearly a third (29\%) use it in every project assignment. Based on the research framework one would expect that all respondents from the top user group would utilise the system, however three of them have abandoned usage and give as a reason that the system is not useful in their current job or that the system is too slow to provide help. In the average user group $57 \%$ of the respondents use the system at the time of the investigation.

The differing percentages concerning system use may be an indication that not all of the users are familiar with the company's KMS framework and rhetoric and indeed only $69 \%$ of all users confirm that they know the framework and its defined processes. This has to be seen in relation to the fact that only $49 \%$ of 
Using IT to Support Knowledge Management

\begin{tabular}{|l|l|l|l|l|l|l|}
\hline & $\begin{array}{l}\text { All } \\
\text { abs. no. }\end{array}$ & $\begin{array}{l}\text { All } \\
\%\end{array}$ & $\begin{array}{l}\text { Top group } \\
\text { abs. no. }\end{array}$ & $\begin{array}{l}\text { Top group } \\
\%\end{array}$ & $\begin{array}{l}\text { Average group } \\
\text { abs. no. }\end{array}$ & $\begin{array}{l}\text { Average } \\
\text { group } \\
\%\end{array}$ \\
\hline General information & 58 & $61 \%$ & 35 & $59 \%$ & 23 & $64 \%$ \\
\hline $\begin{array}{l}\text { Project profiles and ex- } \\
\text { perience }\end{array}$ & 50 & $53 \%$ & 33 & $56 \%$ & 17 & $47 \%$ \\
\hline Knowledge networks & 43 & $45 \%$ & 29 & $49 \%$ & 14 & $39 \%$ \\
\hline Biographies & 19 & $20 \%$ & 14 & $25 \%$ & 5 & $14 \%$ \\
\hline $\begin{array}{l}\text { Reusable software com- } \\
\text { ponents }\end{array}$ & 18 & $19 \%$ & 11 & $19 \%$ & 7 & $19 \%$ \\
\hline $\begin{array}{l}\text { Topic based collabora- } \\
\text { tion }\end{array}$ & 16 & $17 \%$ & 11 & $19 \%$ & 5 & $14 \%$ \\
\hline Project advice & 12 & $13 \%$ & 8 & $14 \%$ & 4 & $11 \%$ \\
\hline Discussion groups & 5 & $5 \%$ & 2 & $3 \%$ & 3 & $8 \%$ \\
\hline Yellow pages & 5 & $5 \%$ & 3 & $5 \%$ & 2 & $6 \%$ \\
\hline
\end{tabular}

Table 2: Usage of the KMS tool functions

(tool users only, percentage given with regard to the total users within the respective group)

the practitioners have gone through a formal training which might entail the danger that not all use the KMS in the intended way.

The numbers do however not say anything about which parts of the system are used and for which concrete purposes they are used.

$69 \%$ of the users state that they apply the system to collect information, but that they also use other sources and media to do so, such as a local hard disk (49\%), paper (25\%) or other databases $(25 \%)$ and that they rely on their own memory (44\%).

With regard to the functions provided by the IT system (see table 2) $61 \%$ use the tool to get general information, $53 \%$ to access project descriptions and $45 \%$ of the users apply it to participate in knowledge networks, $20 \%$ search for biographies, $19 \%$ to find reusable software components, $17 \%$ to co-operate with

\begin{tabular}{|c|c|c|c|c|c|c|}
\hline & $\begin{array}{l}\text { All } \\
\text { abs. no. }\end{array}$ & $\begin{array}{l}\text { All } \\
\%\end{array}$ & $\begin{array}{l}\text { Top group } \\
\text { abs. no. }\end{array}$ & $\begin{array}{l}\text { Top group } \\
\%\end{array}$ & $\begin{array}{l}\text { Average } \\
\text { group } \\
\text { abs. no. }\end{array}$ & $\begin{array}{l}\text { Average } \\
\text { group } \\
\%\end{array}$ \\
\hline $\begin{array}{l}\text { To browse for useful in- } \\
\text { formation }\end{array}$ & 63 & $66 \%$ & 40 & $68 \%$ & 23 & $64 \%$ \\
\hline To store knowledge assets & 46 & $48 \%$ & 32 & $54 \%$ & 14 & $39 \%$ \\
\hline To find project profiles & 39 & $41 \%$ & 30 & $51 \%$ & 9 & $25 \%$ \\
\hline $\begin{array}{l}\text { To find a knowledge-able } \\
\text { colleague }\end{array}$ & 16 & $17 \%$ & 14 & $24 \%$ & 2 & $6 \%$ \\
\hline To find biographies & 14 & $15 \%$ & 9 & $15 \%$ & 5 & $14 \%$ \\
\hline To find a CV & 9 & $9 \%$ & 7 & $12 \%$ & 2 & $6 \%$ \\
\hline $\begin{array}{l}\text { As the primary store for } \\
\text { knowledge assets }\end{array}$ & 21 & $22 \%$ & 16 & $27 \%$ & 5 & $14 \%$ \\
\hline
\end{tabular}

Table 3: Reasons for and Utilisation of the KMS tool

(tool users only, percentage given with regard to the total users within the respective group) 
colleagues on dedicated topics, $13 \%$ to get advice for project work and $5 \%$ to participate in discussion groups and to use the yellow pages of the company.

However to the question of why and how they use the system (see table 3), 66\% answer that they browse the system in general for useful documents, $41 \%$ to find project profiles, $17 \%$ to find a knowledgeable colleague, $15 \%$ to find biographies and $9 \%$ to find CVs. $48 \%$ use the system as a repository for valuable knowledge and documents, but only $22 \%$ as the primary repository for this purpose. Just $52 \%$ submit anything to a network, and of these again $41 \%$ do that 1 to 5 times a year and only $11 \%$ do so more; $46 \%$ never submit anything.

$33 \%$ submit something that they themselves consider new knowledge, respectively an intellectual asset and $16 \%$ update existing knowledge whereas $63 \%$ answer that they search for what they consider an intellectual asset.

The survey did not investigate whether those who submit often are members of the steering boards that have the overall responsibility for the functioning of the KMS or whether they are usual users. Concerning feedback $71 \%$ never give feedback to existing material and only $16 \%$ do so 1 to 5 times a year and the rest less.

The system is used in all project phases, but mainly in the actual sales' phase when a contract is drawn $(35 \%)$ and when the project is performed (33\%), only $14 \%$ use the system when a project is closed which according to the framework should be the phase where project experience in written form should be submitted to the knowledge bases. However somehow contradictory $38 \%$ answer that they use the system to reap knowledge in a project assignment.

With respect to the respondents' job functions, $93 \%$ of all consultants who have answered identified themselves as users, but only $62 \%$ of all replying technical staff. This supports the numbers describing the use purposes of the system for project work.

Again the somewhat different numbers indicate problems with the understanding of the system's intentions and the underlying framework.

\section{Utilisation Problems and Reasons for Non-Adoption}

There are a couple of reasons why people are so hesitant, which are explicitly stated by the respondents of the survey: only $31 \%$ of the system users put forward that the documents are easy to find and that the knowledge base is well structured and only $20 \%$ think that the newest knowledge is available, whereas also $31 \%$ think that the provided information is not up-to-date. Furthermore $29 \%$ declare that the databases are too big and $23 \%$ that they often cannot find what they need. Finally $19 \%$ say that there is simply too much information on the company Web. There are also a few who answer that the approval process which is performed by the steering boards specially assigned for this task - however only part-time - is too slow and not accurate enough. Yet, the biggest obstacles seem to be that the technical infrastructure, namely the internal network is too slow (60\%) and that the employees who are paid based on hours billed to customer projects do not feel that they have time to explore the system (38\%).

This tendency is confirmed by those, who do not use the system: $50 \%$ of them state that they do not have the time to do so. A further $27 \%$ express that the information is not suitable for them and $23 \%$ answer that they never found the information they were looking for and that they therefore have stopped using the system. They use instead exclusively the above-mentioned media, namely databases $(30 \%)$, local hard disks (23\%), network drives (23\%) and paper archives (20\%) and rely on their own memory (40\%).

\section{Discussion}

The data material can be interpreted from different perspectives. 
Using IT to Support Knowledge Management

From one point of view it can be argued that the organisation has problems with its approach to knowledge management. Several reasons for what some might consider as relatively low adoption and use of the IT tool and its underlying framework have been given by the respondents themselves.

Technical advances concerning the internal network capacity might increase the utilisation of the KMS. The same is valid for organisational amendments with regard to the relation of time spent directly on client assignments and time spent on knowledge work. Better information and more training about the framework and its IT support will possibly also enhance the situation. Improving the structuration and approval process, will probably also have a positive effect, but the given reasons might also be an indication for deeper lying problems.

In the literature, basically two approaches to knowledge management and organisational learning are distinguished. In this paper, however, no discussion about the differences about these two concepts is included. Such a discussion can for example. be found in Swan et al. (1999). Knowledge is broadly classified as explicit or tacit, theoretical or practical, individual or collective (for a discussion of the concepts, see for example Kautz \& Thaysen (2001)).

Cook \& Yanow (1993) see one approach where organisations are considered as cognitive entities, there knowledge is understood as a codifable commodity, which can be stored and accessed in databases. Knowledge related processes are clearly distinguished as acquisition and construction, storage, distribution, interpretation and application (see for example. Huber (1991), Pentland (1995)).

The other approach perceives organisations as communities-of-practice. It suggests that even if knowledge is a personal property that the idea of mere cognitive, de-conceptualised acquisition of knowledge is inadequate in a context where people act together (Lave (1993), Elkjær (1999)). Nonaka (1994) argues that knowledge cannot simply be considered as information as it is re-created and re-constituted through interactive, continuous social networking activity, an activity which is performed through participation in, what Brown \& Duiguid (1991) call, communities-of-practice.

Kautz \& Thaysen (2001) put forward that the distinction of different types of knowledge as well as of individual cognitive knowledge processes as opposed to collective knowledge processes, which take place in communities-of-practice makes sense for analytical reasons, but that the two approaches are closely intertwined and supplement each other.

In line with this argument, Hansen et al. (1999) propose two overall strategies for knowledge management, of which one always should be the primary one and the other the supporting secondary one. The socalled codification strategy relies on carefully structured databases and should be applied in a context where a company provides standardised, mature products and services, which can be described in written documents and stored in databases. The other strategy, called personalisation strategy, where technology is only used to mediate communication, should be applied where customised, innovative products and services are provided based on personal collaboration.

The balance of the two strategies is delicate and requires that the company has a clear understanding of its business. It might be that the organisation under investigation here does not have such a clear, shared vision. It seems to heavily rely on a codification strategy where a personalisation strategy might be more adequate. At least the fact that only $28 \%$ of the respondents believe that more than $50 \%$ of the organisation's knowledge can be codified points into this direction.

Another result also needs more analysis. The respondents complain that there is too much information in the databases and that the information is not properly structured. The organisation has good intentions with the establishment of approval teams and thus follows current best practice (see Brown \& Duguid (2000) for another example). It might however indicate that the organisation does not involve the right people in the approval process. Brown \& Duguid (2000) strongly advocate to involve the practitioners who produce and apply the knowledge not only in the submission and general feedback processes, but 
also in the approval process. If only managers and project leaders fill the databases, there is a risk that the repositories only contain what they think is useful for their employees and not what is actually valuable for those. In such cases, the contents of the databases might also appear fragmented and is not used, as shown by for example. Robey et al. (2000).

These authors also point to another technology related problem. Knowledge archived in a database has to be taken as it is. There is little, if no possibility, to interactively negotiate and clarify its contents.

To elucidate uncertainties social interaction is still necessary. Such interaction also supports getting known to each other and to build up trust - both characteristics, which according to Nonaka (1994) are mandatory for sharing knowledge.

From this point of view the respondents' preference for a mixture of knowledge sources and especially communication media appears to be a natural choice to operate in a network of people supported by technology.

Then, the achieved utilisation rate of the IT tool in general - although leaving room for improvement can be considered as not that low. It can be interpreted positively and as a sign for a development in the right direction.

\section{Conclusions}

The preceding presentation and discussion of the survey results has pointed to some questions, both with respect to the organisation under investigation here and the field of knowledge management in general. These are partly related to the research method applied here. Together with the main findings they will now be summarised.

The purpose of the survey instrument used in this study was to get a first impression of the extent and objectives of IT tool utilisation for knowledge management in a large global firm.

The research results indicate that the respondents are not familiar with or have not understood the knowledge management framework underlying the IT tool. Clearly future research should directly inquire how the knowledge management framework and its constituting processes are perceived by the company's employees. It might also be interesting to correlate the different variables with regard to who is using which functionality for what reason and to what degree both in terms of frequency and time spent to get a more differentiated picture of user profiles and usage patterns. Another significant area which represents a difficult and controversially debated topic and which therefore consciously has been excluded from this research is an investigation of the effect of the IT utilisation both in terms of subjective perceptions on an individual level, but also in terms of an economical perspective on the organisational and company level.

The study might also be criticised for the size and selection of its sample. But even if the following results are biased and not representative for the whole organisation, they are valid for a small, but important segment of the company's employees and as such show no less than some note-worthy trends.

In summary, the knowledge management system

- is used by $3 / 4$ of all respondents, about $2 / 3$ use it mainly to search for general information, about $1 / 2$ participate in competence networks

- is mainly used in the marketing phase of project acquisition

- $\quad$ is mainly used by consultants, and less by technical developers

- utilisation is limited due to the practitioners' lack of time

- is little used to participate in the development of knowledge assets 
Using IT to Support Knowledge Management

- is with regard to its various functions not used very much

- framework is not known to the majority of the KMS users

- $\quad$ is not used as the primary repository for knowledge assets

- is slow and has long answer times

- has an inscrutable structure and provides poor search results.

These results and the accompanying discussion give at least an interesting starting point for the company to consider its knowledge management approach and for the research community to perform further investigations.

\section{Acknowledgement}

The author likes to thank for all research assistance provided by the organisation under investigation.

\section{References}

Bresman, H., Birkinshaw, J., Nobel R. (1999). Knowledge Transfer in International Acquisitions, Journal of International Business Studies, 30 (3), 439-462.

Brown, J. S., Duguid, P. (1991). Organisational Learning and Communities-of-Practice: Toward a Unified View of Working, Learning, and Innovation, Organisation Science, 2 (1) , 40-57.

Brown, J. S., Duguid, P. (2000). Balancing Act: How to capture Knowledge without killing it, Havard Business Review, MayJune 2000, 73-80.

Cook, S. D. N., Yanow, D. (1993). Culture and Organizational Learning, Journal of Management Inquiry, 2 (4), 373-390.

Elkjaer, B. (1999). 'In search of a social learning theory', in Easterby-Smith, M., Araujo, L., Burgoyne, J. (eds.), Organisational Learning and the Learning Organisation, Developments in Theory and Practice, Sage, London, UK, 75-91.

Gupta, A. K., Govindarajan (2000). Knowledge Flows within Multinational Corporations, Strategic Management Journal, 21, 473-496

Hansen, M. T. (1999). The Search-Transfer Problem: The Role of Weak Ties in Sharing Knowledge across Organization Subunits, Administrative Science Quarterly, 44, 82-111.

Hansen, M. T., Nohria, N., Tierney, T. (1999). What your strategy for managing knowledge, Havard Business Review, March April, 1999, 106-116.

Huysman, M. (2000). Rethinking organizational learning: analyzing learning processes of information system designers, $A c$ counting, Management \& Information Technology, 10, 81-99.

Huber, G. P. (1991), Organisational Learning: The contributing Processes and the Literatures, Organisation Science, 2 (1), 88115.

Kautz, K., Thaysen, K. (2001). Knowledge, learning and IT Support in a Small Software Company, Journal of Knowledge Management, 5 (4), 349-357.

Lave, J. (1993). The practice of Learning, in S. Chaiklin, J. Lave (eds.), Understanding Practice - Perspectives on activity and context, Cambridge University Press, Cambridge UK, 3-32.

Nonaka, I. (1994). A Dynamic Theory of Organizational Knowledge Creation, Organisation Science, 5 (1), 14-37.

Pentland, B. T. (1995). Information Systems and Organisational Learning: The Social Epistemology of Organisational Knowledge Systems, Accounting, Management \& Information Technology, 5 (1), 1-21.

Robey, D., Khoo, H. M., Powers, C. (2000), Situated Learning in Cross-Functional Virtual Teams, IEEE Transactions on Professional Communication, 43 (1) 2000, 51-66; and Technical Communication, 47 (1) 2000, 51-66. (Joint Special Issue).

Swan, J., Scarbrough, H., Preston, J. (1999), Knowledge Management - The Next Fad to Forget People, in Pries-Heje, J. et al. (eds.) Proceedings of the $7^{\text {th }}$ European Conference on Information Systems, Vol. I-II, June 23-25, 1999, Copenhagen, Denmark, 668-678.

Szulanski, G. (2000)., The Process of Knowledge Transfer: A Diachronic Analysis of Stickiness, Organizational Behavior and Human Decision Processes, 82 (1), 9-2.7 


\section{Biography}

Karlheinz Kautz is professor in systems development and software engineering at the Department for Informatics at Copenhagen Business School. He holds a PhD in systems development and MSc in software development. He is the chair of the IFIP TC 8 WG 8.6 on the adoption and diffusion of IT. His research interests are in systems development, knowledge management, IT diffusion and transfer, as well as software quality and software process improvement.

His work has been published internationally journals and conferences including Information Technology and People, IEEE Software, Information and Software Technology, Journal of Technology Studies, Journal of Human Computer Interaction, Software Process - Improvement and Practice, Journal of Computer Personnel, Organization and Scandinavian Journal of Information Systems, Journal of Knowledge Management. 